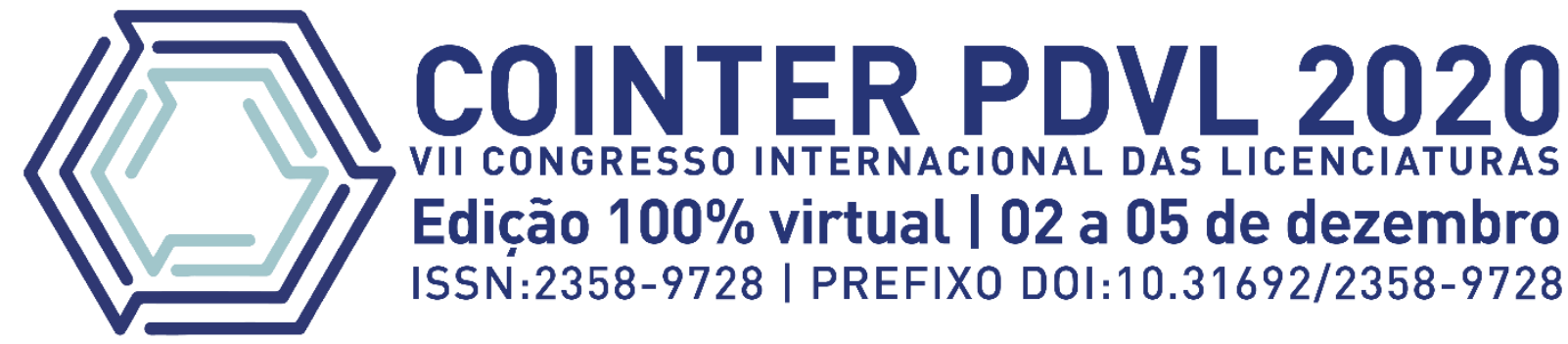

\title{
ANÁLISE DOS REGISTROS DE REPRESENTAÇÃO SEMIÓTICA MOBILIZADOS NAS QUESTÕES DO SAEPE SOBRE FUNÇÃO DO $1^{\circ}$ GRAU
}

\section{ANÁLISIS DE REGISTROS DE REPRESENTACIÓN SEMIÓTICA MOVILIZADOS EN PREGUNTAS SAEPE SOBRE LA FUNCIÓN DEL $1{ }^{\text {er }}$ GRADO}

\section{ANALYSIS OF SEMIOTIC REPRESENTATION RECORDS MOBILIZED IN SAEPE QUESTIONS ABOUT THE FUNCTION OF THE $1^{\text {st }}$ DEGREE}

Apresentação: Comunicação Oral

Alan Gustavo Ferreira ${ }^{1}$; Camila Emili Gonçalo da Hora ${ }^{2}$; Valéria da Silva Santos ${ }^{3}$; Franklin Fernando Ferreira Pachêco $^{4}$;

DOI: https://doi.org/10.31692/2358-9728.VIICOINTERPDVL.0256

\begin{abstract}
RESUMO
O presente trabalho tem por objetivo identificar os registros de representação semióticos mobilizados nos itens propostos na Avaliação Externa do Estado de Pernambuco (SAEPE) e suas transformações semióticas, dos anos de 2015 a 2019, aplicados a alunos do $3^{\circ}$ ano do Ensino Médio. A análise dos itens teve por referência a Teoria de Registros de Representação Semiótica proposta por Raymond Duval que tem premissa que as representações semióticas são indispensáveis para o ensino e aprendizagem da matemática já que, seus objetos não são perceptíveis ou observáveis, eles existem como construções mentais e são conhecidos pelas suas representações. Daí a necessidade de uma atividade de produção semiótica. Trata-se de uma pesquisa qualitativa do tipo Análise Documental. Para tanto, foram selecionados onze itens referentes aos descritores D 19 - Resolver problema envolvendo uma função do $1^{\circ}$ grau, D 22 - Reconhecer o gráfico de uma função polinomial do $1^{\circ}$ grau por meio de seus coeficientes e o D 23 - Reconhecer a representação algébrica de uma função do $1^{\circ}$ grau dado o seu gráfico ou vice e versa, propostos pela matriz curricular do estado de Pernambuco, que abordam o conteúdo de função do $1^{\circ}$ grau, presentes nas avaliações no recorte temporal em tela. Os resultados mostram que para a resolução dos itens propostos, os estudantes precisam mobilizar dois a três registros de representações semióticas que são o registro de língua materna, o registro algébrico e o registro numérico. As análises ainda possibilitaram o entendimento de que se faz necessário fortalecer os conhecimentos dos estudantes nesses itens, uma vez que a mobilização de vários registros é fundamental, mostrando sempre as várias representações que o objeto matemático pode ser representado, inclusive dispondo de recursos tecnológicos para isso.
\end{abstract}

Palavras-Chave: Registro de Representação Semiótica, Avaliação Externa, SAEPE, Função do $1^{\circ}$ grau.

${ }^{1}$ Doutorando em Educação Matemática e Tecnológica, Universidade Federal de Pernambuco, Alan.Gustavo@hotmail.com

${ }^{2}$ Especialista no curso de Pós-Graduação Lato Sensu em Ensino de Matemática pelo Centro de Pesquisa, PósGraduação, Extensão e Atualização (CPPGEA) na Universidade da Vitória de Santo Antão (UNIVISA), hora.goncalo@gmail.com

${ }^{3}$ Mestre em Educação Matemática e Tecnológica, Universidade Federal de Pernambuco, valeriassantos22@ hotmail.com

${ }^{4}$ Doutorando em Educação Matemática e Tecnológica, Universidade Federal de Pernambuco, pacheco.franklin9@gmail.com 


\section{RESUMEN}

El presente trabajo tiene como objetivo identificar los registros de representación semiótica movilizados en los ítems propuestos en la Evaluación Externa del Estado de Pernambuco (SAEPE) y sus transformaciones semióticas, de los años 2015 a 2019, aplicados a estudiantes de 3er año de Bachillerato. El análisis de los ítems se basó en la Teoría de Registros de Representación Semiótica propuesta por Raymond Duval, la cual tiene como premisa que las representaciones semióticas son indispensables para la enseñanza y aprendizaje de las matemáticas ya que, sus objetos no son perceptibles u observables, existen como construcciones mentales. y son conocidos por sus representaciones. De ahí la necesidad de una actividad de producción semiótica. Es una investigación cualitativa del tipo Análisis Documental. Para ello se seleccionaron once ítems referidos a los descriptores D 19 - Resolver un problema que involucre una función de 1er grado, D 22 - Reconocer la gráfica de una función polinomial de 1er grado a través de sus coeficientes y D 23 - Reconocer la representación algebraica de una función del ler grado dada su gráfica o viceversa, propuesta por la matriz curricular del estado de Pernambuco, que aborda el contenido de la función del 1er grado, presente en las evaluaciones en el marco temporal en pantalla. Los resultados muestran que para la resolución de los ítems propuestos, los estudiantes necesitan movilizar de dos a tres registros de representaciones semióticas, que son el registro de la lengua materna, el registro algebraico y el registro numérico. Los análisis también permitieron comprender que es necesario fortalecer el conocimiento de los estudiantes sobre estos ítems, ya que la movilización de varios registros es fundamental, mostrando siempre las diversas representaciones que puede representar el objeto matemático, incluyendo contar con los recursos tecnológicos para hacerlo.

Palabras Clave: Registro de Representación Semiótica, Evaluación Externa, SAEPE, Función de 1er grado

\section{ABSTRACT}

The present work aims to identify the semiotic representation records mobilized in the items proposed in the External Evaluation of the State of Pernambuco (SAEPE) and their semiotic transformations, from the years 2015 to 2019, applied to students of the 3rd year of High School. The analysis of the items was based on the Semiotic Representation Records Theory proposed by Raymond Duval, which has the premise that semiotic representations are indispensable for the teaching and learning of mathematics since, their objects are not perceptible or observable, they exist as mental constructions and are known for their representations. Hence the need for a semiotic production activity. It is a qualitative research of the Documentary Analysis type. For that, eleven items were selected referring to the descriptors D 19 - Solve a problem involving a function of the 1st degree, D 22 - Recognize the graph of a polynomial function of the 1st degree through its coefficients and D 23 - Recognize the algebraic representation of a function of the 1st degree given its graph or vice versa, proposed by the curricular matrix of the state of Pernambuco, which addresses the content of the function of the 1st degree, present in the evaluations in the time frame on screen. The results show that for the resolution of the proposed items, students need to mobilize two to three records of semiotic representations, which are the mother tongue record, the algebraic record and the numerical record. The analyzes also made it possible to understand that it is necessary to strengthen the knowledge of students in these items, since the mobilization of several records is essential, always showing the various representations that the mathematical object can be represented, including having the technological resources to do so.

Keywords: Registration of Semiotic Representation, External Evaluation, SAEPE, Function of the 1st degree

\section{INTRODUÇÃO}

O processo de avaliação tem como objetivo identificar, estimar, investigar e analisar um determinado acontecimento, uma circunstância ou um processo e é algo bastante presente no cotidiano escolar. Os professores realizam esse processo através de observações, registros, 
provas e etc.

A partir desse processo, os professores verificam o que precisa ser feito para que os alunos tenham condições de avançar no sistema escolar. Como afirma Luckesi (1994), a avaliação é uma análise qualitativa sobre dados relevantes do processo ensino-aprendizagem que auxilia o professor a tomar decisões que atenta à realidade de cada unidade escolar.

Quando o processo escolhido pelo professor para avaliar não responde a alguns tipos de questionamentos, como, por exemplo, "se as avaliações dos alunos não é a mesma, ao longo dos anos, como deduzir a melhora ou piora da educação em uma escola, cidade, município ou estado?" surge a avaliação externa que afere de modo uniforme os alunos que possuem diferentes professores, pois, por se tratar de uma avaliação em larga escala, ela não foca apenas nos alunos, mas também na escola, no município, no estado ou no país, avaliando de maneira independente a educação de uma determinada região.

No âmbito nacional, o Brasil possui o SAEB (Sistema de Avaliação da Educação Básica), criado em 1990, é um conjunto de avaliações em larga escala que permite ao Instituto Nacional de Estudos e Pesquisas Educacionais Anísio Teixeira (INEP) fazer uma análise da educação básica do Brasil e de fatores que podem intervir no desempenho dos estudantes.

No âmbito estadual, em Pernambuco temos o SAEPE (Sistema de Avaliação Educacional de Pernambuco), é o principal instrumento de avaliação de desempenho dos estudantes da rede pública estadual e municipal, seu foco principal é avaliar estudantes ao final das etapas de escolaridades nas disciplinas de língua portuguesa e matemática, tendo por objetivo promover as mudanças na educação oferecida pelo Estado, avistando a oferta de um ensino de qualidade.

O SAEPE observa o grau de domínio dos estudantes nas habilidades e competências que são consideradas essenciais para o avanço no sistema escolar, através de testes padronizados (SAEPE, 2017). Ele respeita as Matrizes de referências que são habilidades selecionadas, sendo estas passíveis de aferição por meio de testes padronizados de desempenho que sejam, ainda, relevantes e representativas de cada etapa de escolaridade. Formada por um conjunto de descritores que explicitam dois pontos básicos do que se pretende avaliar: o conteúdo programático a ser avaliado em cada período de escolarização e o nível de operação mental necessário para a realização de determinadas tarefas. (SAEPE, 2011).

Nas matrizes de referência para avaliação em Matemática do estado de Pernambuco, os temas são organizados em quatro grandes campos: Geometria, Grandezas e Medidas, Números e Operações/Álgebra e Funções e Tratamento da Informação. O desempenho dos estudantes é medido pela Teoria de Resposta ao Item (TRI) que possibilita a comparação de 
resultados ao longo do tempo e pela Teoria Clássica dos Testes (TCT) que identifica percentuais de acerto na prova.

Com relação ao conteúdo de função do $1^{\circ}$ grau, objeto matemático de estudo deste trabalho, os descritores que os contemplam estão dispostos da seguinte maneira:

Quadro 01: Descritores da Matriz de Referência

\begin{tabular}{|c|c|c|}
\hline Ano & Campo & Descritor \\
\hline $\begin{array}{l}3^{\circ} \text { ano do Ensino } \\
\text { Médio }\end{array}$ & Álgebra & $\begin{array}{l}\text { D19 - Resolver problema envolvendo uma função do } \\
1^{\circ} \text { grau }\end{array}$ \\
\hline $\begin{array}{l}3^{\circ} \text { ano do Ensino } \\
\text { Médio }\end{array}$ & Álgebra & $\begin{array}{l}\text { D22 - Reconhecer o gráfico de uma função } \\
\text { polinomial do } 1^{\circ} \text { grau por meio de seus coeficientes }\end{array}$ \\
\hline $\begin{array}{l}3^{\circ} \text { ano do Ensino } \\
\text { Médio }\end{array}$ & Álgebra & $\begin{array}{l}\text { D23 - Reconhecer a representação algébrica de uma } \\
\text { função do } 1^{\circ} \text { grau dado o seu gráfico ou vice e versa }\end{array}$ \\
\hline
\end{tabular}

Fonte: Autoria Própria (2020)

Os itens que foram selecionados fazem parte da constituição do campo da álgebra, pois, segundo o SAEPE (2019), é nesse campo que os estudantes são capazes de traduzir uma situação dada em uma expressão algébrica ou representação gráfica e, é através do pensamento algébrico que eles se tornam preparados para resolver determinado problema, assim, consegue generalizar o raciocínio utilizado para resolver problemas de mesma natureza.

As questões são referentes ao conteúdo de função do $1^{\circ}$ grau, pois nesse conteúdo encontramos um maior comprometimento em tentar compreender as habilidades e transformações supracitadas. As questões foram aplicadas nas avaliações nos anos de 2015 a 2019, a alunos do $3^{\circ}$ ano do Ensino Médio.

Procurando identificar os registros de representação semiótica mobilizados, considerando os itens que possibilitam a mobilização dos registros de representação no SAEPE, foi levantado o seguinte questionamento: Quais os Registros de Representação Semiótica mobilizados e quais transformações semióticas são realizadas, nas questões do SAEPE dos anos de 2015 a 2019 aplicadas aos estudantes do $3^{\circ}$ ano do Ensino Médio?

Assim sendo, o referencial teórico para essa pesquisa é a Teoria de Registros de Representação Semiótica de Duval (2010), pois adotamos o pressuposto de que o trabalho com diferentes registros de representação de um objeto matemático favorecem a compreensão do conteúdo de função do $1^{\circ}$ grau, para que o estudante consiga fazer os devidos reconhecimentos do objeto estudado.

Os dados foram coletados através do banco de dados disponibilizado pela instituição 
que elabora e desenvolve o SAEPE o Centro de Políticas Públicas e Avaliação da Educação (CaEd) que é administrado pela Universidade Federal de Juiz de Fora (UFJF).

Essa análise revela-se de suma importância, pois pode-se identificar o que está sendo estabelecido em relação ao Ensino de Matemática no Brasil, mais precisamente em Pernambuco, contribuindo para a melhora e uma busca de estratégias tanto de ensino como de aprendizagem.

\section{FUNDAMENTAÇÃO TEÓRICA}

A Teoria dos Registros de Representação Semiótica desenvolvida pelo filósofo e psicólogo francês Raymond Duval, afirma que as representações semióticas são indispensáveis para o ensino e aprendizagem da matemática, para ele as "representações semióticas são produções constituídas pelo emprego de signos pertencentes a um sistema de representações que tem inconvenientes próprios de significação e de funcionamento" (DUVAL, 2012, p. 269).

As representações semióticas em Matemática são indispensáveis não apenas para fins de comunicação, mas também para o seu desenvolvimento pois, o modo de acesso aos objetos de conhecimento matemático é diferente daquele conduzido por outras disciplinas e, por essa característica. Assim, é por meio das representações semióticas que o objeto do conhecimento matemático se torna acessível para sua apreensão.

Segundo Duval (2012), para ter uma compreensão em Matemática se faz necessário distinguir corretamente o objeto de suas representações. Segundo o autor, para dissociar o objeto de sua representação, o sujeito deve mobilizar diferentes registros de representação semiótica do mesmo objeto matemático. Duval (2012) utiliza o termo registro para designar os diferentes tipos de representações utilizadas em matemática, tais como algébrico, gráfico, língua natural e figural. Um registro de representação semiótica pode apresentar dois tipos de transformações: o tratamento e a conversão.

O Tratamento de uma representação corresponde a uma transformação de representação interna a um registro de representação ou a um sistema. Existem dois tipos de tratamentos, os quase-instantâneos e os intencionais. Os tratamentos quase-instantâneos "são aqueles efetuados antes mesmo de terem sido marcados e produzem as informações e as significações em que um sujeito tem imediatamente consciência”. (DUVAL, 2009, p. 50-51). E os tratamentos intencionais "são aqueles que tomam ao menos o tempo de um controle consciente para ser efetuado e que se apoiam exclusivamente sobre os dados provisoriamente remarcados, numa percepção furtiva do objeto" (Op. Cit., p. 52). 


\section{ANÁLISE DOS REGISTROS DE REPRESENTAÇÃO SEMIÓTICA}

A Conversão de representação corresponde à transformação de uma representação de um registro considerado de partida, para outro registro considerado de chegada, mantendo totalmente ou em parte o conteúdo da representação de partida. A transformação de um gráfico de uma função para sua representação algébrica é um exemplo de conversão.

Segundo Duval (2010) a variedade dos registros de representação semiótica, necessários ao funcionamento matemático, admite a seguinte classificação:

Quadro 02: Classificação dos diferentes registros mobilizáveis na atividade matemática

\begin{tabular}{|c|c|c|}
\hline & $\begin{array}{c}\text { REPRESENTAÇÃO } \\
\text { DISCURSIVA }\end{array}$ & $\begin{array}{c}\text { REPRESENTAÇÃO NÃO- } \\
\text { DISCURSIVA }\end{array}$ \\
\hline REGISTROS & Língua Natural & Figuras geométricas planas ou em \\
\hline $\begin{array}{l}\text { MULTIFUNCIONAIS } \\
\text { (não-algoritmizáveis) }\end{array}$ & $\begin{array}{l}\text { Associações verbais (conceituais) } \\
\text { Forma de raciocinar: } \\
\text { - Argumentação a partir de } \\
\text { observações, de crenças...; } \\
\text { - Dedução válida a partir de } \\
\text { definição ou de teoremas. }\end{array}$ & $\begin{array}{l}\text { perspectivas (configurações em } \\
\text { dimensões } 0,1,2 \text { ou } 3 \text { ). } \\
\text { - Apreensão operatória e não } \\
\text { somente perceptiva; } \\
\text { - } \text { Construção } \\
\text { instrumentos. com }\end{array}$ \\
\hline $\begin{array}{l}\text { REGISTROS } \\
\text { MONOFUNCIONAIS } \\
\text { (algoritmizáveis) }\end{array}$ & $\begin{array}{l}\text { Sistemas de escrita: } \\
\text { - Numéricas } \\
\text { decimal, fracionária...); } \\
\text { - Algébricas; } \\
\text { - Simbólicas } \\
\text { formais). } \\
\text { Cálculo }\end{array}$ & $\begin{array}{l}\text { Gráficos Cartesianos. } \\
\text { - Mudanças de sistema de } \\
\text { coordenadas; } \\
\text { - Interpolação, extrapolação. }\end{array}$ \\
\hline
\end{tabular}

Fonte: Duval (2010, p.14).

Segundo Karrer (2016), na compreensão matemática é importante estabelecer a conversão entre pelo menos um registro monofuncional e um registro multifuncional. Quanto maior a mobilização entre os registros maior assimilação conceitual do objeto matemático (DAMM, 1999).

O estudo teórico dos Registros de Representação Semiótica possibilitou a análise dos itens do SAEPE para o terceiro ano do Ensino Médio, bem como contribuiu para a seleção e organização dos itens considerando as possibilidades de exploração, enfatizando as transformações entre os registros. 


\section{REVISÃO DE LITERATURA}

Com o propósito de conhecer as pesquisas realizadas sobre ensino e aprendizagem da matemática baseada na Teoria de Registros de Representação Semiótica realizamos várias pesquisas no banco de dados de teses e dissertações do Repositório Digital da UFPE, no Sistema de Publicação Eletrônica de Teses e Dissertações (TEDE), na Revista Eletrônica de Educação Matemática (REVEMAT) e no Programa de pós-graduação em ensino de ciências e educação matemática da UEL que possuem extenso acervo de pesquisas.

Através das análises dos títulos e dos resumos, encontramos cinco pesquisas que consideramos relevantes sobre a Teoria e suas diversas formas de abordagem. No quadro 3 apresentaremos essas cincos pesquisas agrupadas em ordem alfabética pelo nome do autor, o título do trabalho e o ano de publicação.

Quadro 03: Pesquisas encontradas que tratam da Teoria de Representação Semiótica

\begin{tabular}{|c|c|c|}
\hline Autor (es) & Título & Ano \\
\hline $\begin{array}{c}\text { Deise Pedroso Maggio; } \\
\text { Maria Arlita da Silveira } \\
\text { Soares; Cátia Maria Nehring }\end{array}$ & $\begin{array}{l}\text { Registros de Representação Semiótica da Função Afim: } \\
\text { análise de livros didáticos de Matemática no Ensino } \\
\text { Médio }\end{array}$ & 2010 \\
\hline Jose Zucco & $\begin{array}{l}\text { Função Monotônicas: Alunos da } 3^{\mathrm{a}} \text { série do Ensino } \\
\text { Médio frente as Olimpíadas de matemática das escolas } \\
\text { publicas. }\end{array}$ & 2010 \\
\hline Lidiane Pereira de Carvalho & $\begin{array}{l}\text { Um estudo das concepções de estudantes do Ensino } \\
\text { Médio sobre o conceito de função com base na Teoria } \\
\text { dos Registros de representação Semiótica }\end{array}$ & 2017 \\
\hline $\begin{array}{c}\text { Nilton Cesar Garcia } \\
\text { Salgueiro }\end{array}$ & $\begin{array}{l}\text { Como estudantes do Ensino Médio lidam com Registro } \\
\text { de Representação Semiótica de Funções }\end{array}$ & 2011 \\
\hline $\begin{array}{c}\text { Raquel Taís Breuning; Cátia } \\
\text { Maria Nehring }\end{array}$ & $\begin{array}{c}\text { Análise de questões do SAERS e o ensino da álgebra na } \\
\text { perspectiva dos Registros de Representação }\end{array}$ & 2011 \\
\hline
\end{tabular}

Fonte: Autoria Própria (2020)

A pesquisa de Maggio et. al (2010), sob a luz da Teoria de Registros de representação Semiótica, apresentaram a análise de como dois livros didáticos de matemática propõem atividades referentes ao conceito de função afim e que reflexos tem na prática pedagógica do 
professor. A pesquisa concluiu que um livro prioriza situações-problemas, enquanto o outro realça problemas "fechados" e não exigem raciocínio matemático dos alunos, fazendo com que acarretem prejuízos no ensino aprendizagem de função afim, pois o livro didático é o principal recurso didático dos professores.

A pesquisa de Zucco (2010) teve como principal objetivo analisar o desempenho de 20 alunos do $3^{\circ}$ ano do Ensino Médio da Rede Pública Estadual na resolução de quatro itens envolvendo funções monotônica (crescente e decrescente) propostas na OBMEP nos anos de 2005 a 2009. Com isso, o autor indicou dificuldades na interpretação dos enunciados das questões bem como as ações relacionadas aos tratamentos e mudança de Registro de Representação Semiótica, revelando a não familiaridade dos estudantes com as questões propostas.

A pesquisa de Carvalho (2017), foi proposto o uso articulado de diferentes representações semióticas utilizando o software GeoGebra para elaborar, aplicar e validar uma situação didática para o ensino do conceito de função fundamentada na Teoria de Registros de Representação Semiótica. Essa pesquisa tinha como objetivo avaliar as contribuições e limitações do uso dessa situação didática pautada no uso de múltiplas representações para aprendizagem do conceito de função. A pesquisa revelou uma maior dificuldade nas tarefas de conversão entre diferentes representações semióticas e na identificação dos domínios das funções o que sugere a precisão de mais discussões e tempo para ampliação dessas habilidades.

A pesquisa de Salgueiro (2011) investigou como estudantes do Ensino Médio de uma escola de Rolândia - PR lidam com o conceito de função ao se depararem com uma sequência didática, nos moldes da engenharia didática trabalhando com os diversos registros de representação semiótica desse objeto matemático. A sequência didática possibilitou aos estudantes a realização de conversões entre os registros de representação semiótica abordados.

Na pesquisa de Breuning e Nehring (2011), foram analisados itens disponíveis da avaliação do SAERS, dos períodos de 2007 a 2009, aplicadas para estudantes do primeiro ano do Ensino Médio, considerando os Registros de Representações Algébricos e suas transformações. Foram selecionados itens com maior possibilidade de mobilização dos Registros Algébricos e foi constatada que é dada a maior ênfase nos Registros numéricos e no tratamento não dando importância nos Registros Algébricos e na conversão.

Com a análise dessas pesquisas, observamos que a Teoria de Registros de Representação Semiótica contribui para muitos estudos na área de Educação Matemática, mas precisamente no nosso objeto de estudo de função do $1^{\circ}$ grau, podemos verificar, também, as grandes análises de itens referentes as avaliações externas, onde nossa pesquisa se inclui. 


\section{METODOLOGIA}

Essa pesquisa tem um caráter qualitativo, pois tem como principal característica a construção da realidade e tem o pesquisador como o instrumento principal da coleta de dados. Segundo Richardson (1999), uma pesquisa qualitativa é uma forma adequada para entender a natureza de um fenômeno social, pois esse tipo de pesquisa avalia a qualidade das informações e não se preocupa com medidas, além disso, é uma pesquisa documental, pois será analisado documentos que foram acessados na plataforma da instituição que organiza o SAEPE, o CaEd.

Foram usadas técnicas de leitura, compreensão, interpretação e análise dos cadernos de provas disponibilizada na plataforma.

A coleta de dados da pesquisa foi realizada através do acesso a plataforma do CaEd, onde encontramos os resultados dos testes cognitivos, informações sobre elementos que compõem a avaliação externa e outros materiais de apoio. Nesse trabalho, focaremos nessa última parte, onde estão disponíveis os cadernos de testes que serão utilizados na pesquisa.

Os cadernos de testes do $3^{\circ}$ anos do Ensino Médio são elaborados em quatro versões: C1201, C1202, C1203, C1204, com exceção do ano de 2016, que tivemos a realização de duas aplicações do SAEPE, por isso, nesse referido ano tivemos oito versões C1201, C1202, C1203, C1204 referente à primeira aplicação (chamaremos de 2016.1) e C1206, C1207, C1208 e C1209 referentes à segunda aplicação (titularemos de 2016.2).

Os cadernos são constituídos de questões iguais, se diferem, apenas quanto à ordem que as questões são distribuídas. São compostos de questões de Língua Portuguesa e Matemática, contabilizando um total de 52 questões, as questões são divididas igualmente entre as disciplinas avaliadas, ou seja, 26 questões de língua portuguesa e 26 de matemática.

Como nosso objetivo é identificar os registros de representação semióticos mobilizados e as transformações semióticas nos itens propostos nas avaliações dos anos de 2015 a 2019 aplicados a alunos do $3^{\circ}$ ano do Ensino Médio referentes aos descritores D19, D22 e D23, utilizamos o caderno nomeado de C1201 de todos os anos e C1206 do ano de 2016.1, para que nossos dados fiquem mais organizados e uniformes.

Após a leitura e compreensão da avaliação, selecionamos as questões que evidenciam claramente os descritores referentes à pesquisa. Os itens selecionados de acordo com o ano de aplicação e o descritor correspondente foram os seguintes:

Descritor 19 - Resolver problema envolvendo uma função do $1^{\circ}$ grau

○ $\quad$ Ano 2015 - Questão 18 

○ $\quad$ Ano 2016.1 - Questão 44
○ Ano 2016.2 - Questão 51
○ $\quad$ Ano 2017 - Questão 21
○ Ano 2018 - Questão 41

Descritor 22 - Reconhecer o gráfico de uma função polinomial do $1^{\circ}$ grau por meio de seus coeficientes

○ Ano 2016.1 - Questão 40

○ $\quad$ Ano 2017 - Questão 18

Descritor 23 - Reconhecer a representação algébrica de uma função do $1^{\circ}$ grau dado o seu gráfico ou vice e versa

○ Ano 2015 - Questão 51

○ Ano 2016.2 - Questão 26

○ Ano 2018 - Questão 50

○ Ano 2019 - Questão 47

O próximo tópico aborda a análise e discussões dos resultados.

\section{RESULTADOS E DISCUSSÃO}

As análises dos dados foram feitas com base nos documentos informados na plataforma do CaEd. Na plataforma são encontradas todas as provas dos anos referidos. Dentro os itens que compunham as avaliações, foram selecionados os onze itens que apresentavam mobilização dos Registros de Representação Semiótica relacionados os descritores 19, 22 e 23.

Analisaremos cada descritor separadamente, descrevendo as habilidades que cada um apresenta e destacaremos os registros de representação semióticos mobilizados por cada questão.

Descritor 19 - Resolver problema envolvendo uma função do $1^{\circ}$ grau

Nos itens relacionados a esse descritor, respeitando a habilidade estabelecida por ele, às questões de todos os anos em que esteve presente, apresentam as mesmas características: temos um enunciado que apresenta um problema típico de uma função do $1^{\circ}$ grau, onde é apresentada a relação entre dois conjuntos como, por exemplo, na situação proposta do ano de 2016.1 (figura 01), podemos informar que o salário de um técnico agrícola depende (está em função) da quantidade de horas extras trabalhadas por ele em um determinado mês. 
Figura 01: Item proposto no SAEPE no ano de 2016, $1^{\text {a }}$ aplicação.

44) (M100085EX) Um técnico agrícola recebe mensalmente um salário fixo de $\mathrm{R} \$ 500,00$, mais $\mathrm{R} \$ 20,00$ por hora extra trabalhada.

Quanto recebeu esse técnico no mês em que fez 15 horas extras?
A) $R \$ 500,00$
B) $\mathrm{R} \$ 520,00$
C) $\mathrm{R} \$ 535,00$
D) $R \$ 600,00$
E) $R \$ 800,00$

Fonte: SAEPE 2016, $1^{\circ}$ aplicação, Caderno C1201, p 18.

No ano de 2015 e nas duas aplicações do ano de 2016, onde os enunciados diferiam apenas da situação problema proposta, para alcançar a resposta o estudante necessita converter o registro de língua materna em registro algébrico e, para isso é necessário que ele tenha um conhecimento de que uma função é uma relação estabelecida entre duas variáveis e que a lei de formação de uma função do primeiro grau é dada por: $\mathrm{f}(\mathrm{x})=\mathrm{ax}+\mathrm{b}$, onde para cada valor de $\mathrm{x}$, podemos determinar um valor de y, ou seja, y está em função de x. Realizando as devidas substituições, as respostas desses itens apresentam-se por meio da representação numérica.

O item proposto no ano de 2017 (figura 02) difere dos anos anteriores apenas na forma de ser apresentado, pois era solicitado que se encontrasse o valor da variável dependente, porém os procedimentos de resolução são os mesmos dos itens apresentados nos anos anteriores.

Figura 02: Item proposto no SAEPE no ano de 2017.

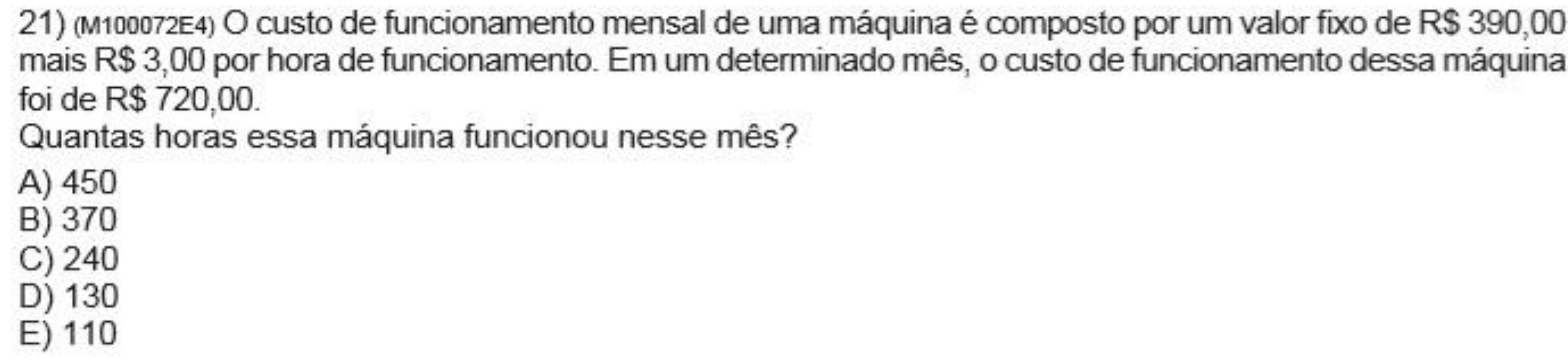
mais $\mathrm{R} \$ 3,00$ por hora de funcionamento. Em um determinado mês, o custo de funcionamento dessa máquina foi de $R \$ 720,00$.

Quantas horas essa máquina funcionou nesse mês?
A) 450
B) 370
C) 240
D) 130
E) 110

Fonte: SAEPE 2017, Caderno C1201, p 10.

Os itens relacionados com o descritor 19, nos anos de 2015, 2016.1, 2016.2 e 2017 apresentam dois tipos de registros: a língua materna e o algébrico, como isso, seria mobilizada a conversão do registro de língua materna em registro algébrico, além de um tratamento dentro do registro algébrico. 


\section{ANÁLISE DOS REGISTROS DE REPRESENTAÇÃO SEMIÓTICA}

No item proposto em 2018, temos um enunciado que apresenta os mesmos tipos de representação semiótica dos anos anteriores, o registro de língua materna e o registro algébrico. Dentro do que o descritor determina a resolução desse item se dá por meio da função do $1^{\circ}$ grau. A resposta apresenta-se por meio do registro numérico.

Neste caso, seria mobilizado um tratamento dentro do registro algébrico, pois o próprio enunciado já fez a conversão do registro de língua materna para o registro algébrico.

Figura 03: Item proposto no SAEPE no ano de 2018

41) (M120014ES) Uma empresa de arquitetura paga o salário de seus funcionários de acordo com a função apresentada no quadro abaixo.

$$
y=2230+1100 x
$$

Nessa função, y representa o salário mensal pago pela empresa de arquitetura ao profissional e $x$ é o número de projetos desse funcionário que foram aprovados no mês.

Qual foi o salário de um profissional que teve 3 de seus projetos aprovados em um mês?
A) $R \$ 2230,00$
B) R\$ 3300,00
C) $R \$ 3330,00$
D) $R \$ 5530,00$
E) R\$ 9990,00

Fonte: SAEPE 2018, Caderno C1201, p 18.

Com as análises dos itens propostos abordando esse tipo de descritor que tem como habilidade resolver um problema envolvendo uma função do $1^{\circ}$ grau, verificamos que mesmo com diferentes situações problemas e diferentes tipos de abordagem do conteúdo, são mobilizados os mesmos registros. Detectando que para se resolver um problema envolvendo uma função de $1^{\circ}$ grau é necessário mobilizar três tipos de registros: o registro de língua materna, o registro algébrico e o registro numérico.

\section{Descritor 22 - Reconhecer o gráfico de uma função polinomial do $1^{\circ}$ grau por meio de seus coeficientes}

A habilidade solicitada por esse descritor refere-se a identificar o gráfico de uma função do $1^{\circ}$ grau a partir dos valores de seus coeficientes angular e linear. Esse descritor foi abordado nos anos de 2016.1 e 2017. Com o olhar para os itens, é possível identificar o Registro de Língua Materna e o Registro Gráfico.

Nesse tipo de questão é necessário que o estudante conheça as características dos coeficientes de uma função do $1^{\circ}$ grau: o coeficiente angular, representado pela letra a, e o coeficiente linear, caracterizado pela letra $b$, pois o enunciado informa os valores correspondentes a cada coeficiente. 
FERREIRA, A. G.; DA HORA, C. E. G; SANTOS, V. S.; PACHÊCO, F. F. F.

Com esses dados propostos no enunciado, o aluno deve compreender que é o coeficiente angular que determinará a inclinação da reta no gráfico, classificando a função em crescente ou decrescente, e que o coeficiente linear é o ponto de intersecção do gráfico com o eixo y, no item apresentado na figura 04 o ponto em que a reta toca no eixo y deve ser o valor igual a 2 .

Sabendo disso, o aluno consegue estabelecer a conversão do registro de língua materna em registro gráfico.

Figura 04: Item proposto no SAEPE no ano de 2016, $1^{\text {a }}$ aplicação.

40) (M120227H6) A função polinomial do $1^{\circ}$ grau $\mathrm{f}: \mathrm{IR} \rightarrow$ IR possui coeficientes angular e linear igual a 2. A representação gráfica dessa função f é

A)

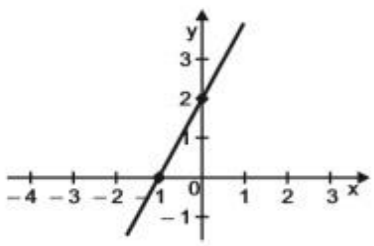

C)

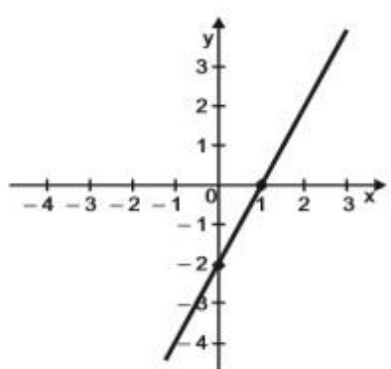

E)

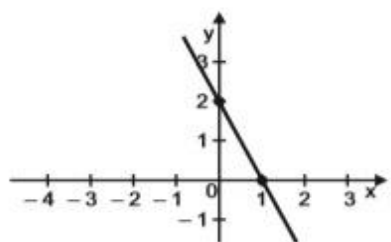

B)

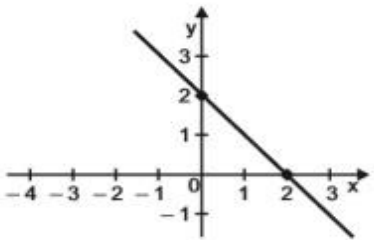

D)

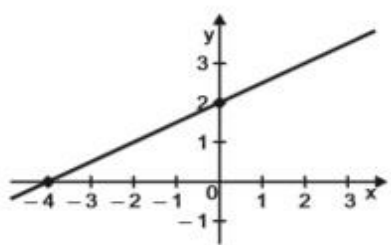

Fonte: SAEPE 2016, 1ª aplicação, Caderno C1201, p 17.

As análises referentes a esse descritor mostram que é necessário a mobilização de dois registros de representação semiótica: Registro de Língua Materna e o Registro Gráfico, salientando que segundo Duval (2012) para ocorrer a aprendizagem matemática é necessário a mobilização de, pelo menos, dois registros de representação de um mesmo objeto matemático.

\section{Descritor 23 - Reconhecer a representação algébrica de uma função do $1^{\circ}$ grau dado o seu gráfico ou vice e versa}

Reconhecer a lei de formação de uma função do $1^{\circ}$ grau dada o seu gráfico ou vice-versa é a habilidade solicitada por esse descritor. Abordado nas avaliações dos anos de 2015, 2016.2, 2018 e 2019.

As questões dos anos de 2015, 2018 e 2019 apresentaram uma mesma característica é 


\section{ANÁLISE DOS REGISTROS DE REPRESENTAÇÃO SEMIÓTICA}

solicitado que observe a representação gráfica de uma função do $1^{\circ}$ grau e, assim, como pergunta final, marcar a alternativa que contenha a representação algébrica referente a esse registro gráfico.

Nesses tipos de itens fica evidente, a utilização dos registros gráfico e algébrico. $\mathrm{O}$ registro gráfico é expresso através do plano cartesiano e, por ser uma função do $1^{\circ}$ grau, a representação gráfica se dá através de uma reta. Com o olhar para o gráfico é possível que o aluno consiga identificar se a função é do tipo crescente ou decrescente basta apenas verificar a inclinação da reta. Observando a questão do ano 2019 (Figura 05) podemos perceber que a inclinação da reta é crescente.

Figura 05: Item proposto no SAEPE no ano de 2019.

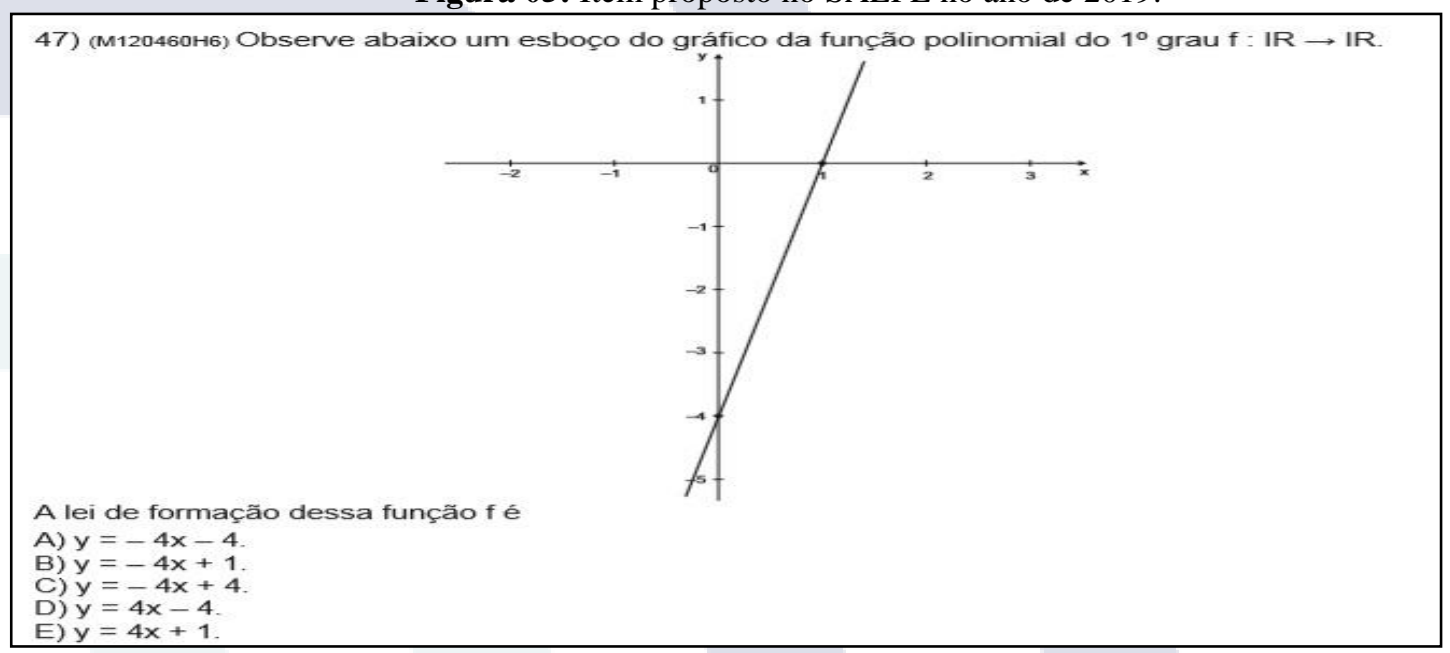

Fonte: SAEPE 2019, Caderno C1201, p 23.

Com isso, sabemos que o coeficiente angular é maior que zero. Além disso, tendo o conhecimento que o coeficiente $\mathrm{b}$, é o ponto de intersecção do gráfico com o eixo y, encontramos $b=-4$, obtendo como lei de formação $F(x)=a x-4$. Conhecendo as coordenadas de um dos pontos, podemos determinar a lei de formação substituindo o valor do y e do $\mathrm{x}$, encontrando, assim, o valor do coeficiente a, e a lei de formação se completa: $F(x)=4 x-4$. Convertendo o registro gráfico para o registro algébrico.

A questão abordada no ano de 2016.2 trouxe o enunciado de forma mais contextualizada conforme a figura 06 e nele detectamos o registro de língua materna. 
Figura 06: Item proposto no SAEPE no ano de 2016, $2^{\mathrm{a}}$ aplicação.

26) (M120660ES) Um vendedor recebe um salário composto de uma parte fixa acrescida de uma parte variável, que corresponde à comissão sobre o total vendido no mês. O salário $\mathrm{S}$ em função do total $\mathrm{x}$ de vendas mensais pode ser visualizado no gráfico abaixo.

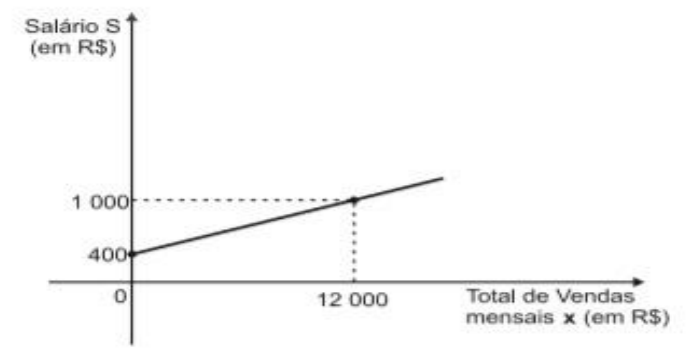

Qual das funções representa o salário desse vendedor?
A) $S=0,05 x+1000$
B) $S=0,05 x+400$
C) $S=20 x+1000$
D) $S=20 x+400$
E) $S=20 x-8000$

Fonte: SAEPE 2016, 2a aplicação, Caderno C1206, p 9.

Não informou no enunciado que se tratava de uma conversão do registro gráfico para o algébrico. A questão refere-se a um problema de função do $1^{\circ}$ grau, ela informa que um vendedor recebe um salário composto de uma parte fixa acrescida de uma variável. Além disso, informa que o salário $\mathrm{S}$ está em função das vendas mensais (x). O enunciado demostra que nem sempre as funções são expressas com as mesmas variáveis, nesse caso o plano cartesiano vem especificando que no eixo $\mathrm{x}$ encontramos total de vendas mensais em reais e o eixo y corresponde ao salário $\mathrm{S}$ também em reais, diferente das outras questões abordadas nos anos anteriores e posteriores a esse item.

Não diferente das questões analisadas anteriormente, analisando o registro gráfico, é possível identificar a inclinação da reta, nesse caso, crescente, além disso, identificamos o ponto de intersecção $b=400$, como isso, a lei de formação fica expressa da seguinte forma: $S=a x+$ 400, utilizando a coordenada perceptível no gráfico $(12000,1000)$, substituindo na lei de formação, conseguimos encontrar o valor referente ao coeficiente assim, encontra-se a representação algébrica referente ao gráfico.

Com as análises de todos os itens referentes a esse descritor em que é necessário que o estudante reconheça a lei de formação de uma função do $1^{\circ}$ grau dada a sua representação gráfica, é possível concluir que o estudante vai mobilizar pelo menos dois registros: o gráfico e o algébrico. 


\section{CONCLUSÕES}

Essa pesquisa tem por objetivo analisar os itens que compõe a avaliação educacional externa em larga escala de Pernambuco, o SAEPE, procurando identificar os Registros mobilizados nas questões aplicadas a estudantes do $3^{\circ}$ ano do Ensino Médio.

Para a elaboração dos dados, analisamos os itens da avaliação dos anos de 2015 a 2019, selecionando onze itens pertencentes aos descritores 19, 22 e 23 que fazem parte da matriz curricular de matemática do estado de Pernambuco, referente ao conteúdo de função do $1^{\circ}$ grau.

Com leitura, a interpretação e a compreensão dos dados foram possíveis identificar que nos itens referente ao descritor 19 abordados em cinco avaliações e que tem como habilidade resolver um problema envolvendo uma função do $1^{\circ}$ grau, os itens foram apresentados de forma direta, possuindo enunciado típico de problemas de função afim, porém foi possível detectar em alguns anos situações problemas relacionadas a essa habilidade.

Esses itens possibilitam que o estudante mobilize três registros: o registro de língua materna, o registro algébrico e o registro numérico, mesmo as questões apresentadas de forma direta ou contextualizadas. É possível ainda encontrar uma única forma de tratamento dentro dos registros algébricos e em alguns anos a conversão do registro de língua materna para o registro algébrico.

Os itens propostos pelo descritor 22 tem a habilidade de reconhecer o gráfico de uma função polinomial do $1^{\circ}$ grau por meio de seus coeficientes, nessas questões faz-se necessário o conhecimento das características de cada coeficiente de uma função do $1^{\circ}$ grau. Esse descritor esteve presentes nos anos de 2016, $1^{\text {a }}$ aplicação, e no ano 2017, sendo oferecido de forma bem direta, informando os valores dos dois coeficientes. Com isso, podemos identificar a mobilização da conversão de dois registros: língua materna para o registro gráfico.

Já a analise dos itens referente ao D23 propôs que os estudantes mobilizassem, também, dois registros o de língua materna e o gráfico, ele esteve presente em quatro avaliações e foi apresentados com enunciados de forma direta e contextualizados, pois esse descritor tem como habilidade, reconhecer a representação algébrica de uma função dado o seu gráfico.

Com isso, evidencia-se que em todos os itens e em todos os descritores que abordam o conteúdo de função do $1^{\circ}$ grau, é possível que os estudantes mobilizem mais de dois registros, possibilitando assim, a compreensão integral do conteúdo, pois segundo as concepções de Duval (2012, p.282) “a compreensão (integral) de um conteúdo conceitual repousa sobre a coordenação de ao menos dois registros de representação".

Além disso, observamos que nos itens podemos identificar os dois tipos de transformação, o tratamento e a conversão, o tratamento no que se diz respeito, principalmente, 
ao descritor 19, que teve o cálculo como principal forma para a resolução da representação algébrica e a conversão mobilizada no descritor 22: registro de língua materna $\rightarrow$ registro gráfico e no descritor 23: registro gráfico $\rightarrow$ registro algébrico.

Através dessas análises faz-se necessário fortalecer os conhecimentos dos estudantes nesses itens onde é necessária a mobilização de vários registros, mostrando sempre as várias representações que o objeto matemático pode ser representado.

O papel do professor nesse fortalecimento dos conhecimentos é de suma importância, por isso é necessário que sejam feitas formações em que essa mobilização através da Teoria de Registros de Representação Semiótica seja o principal objetivo.

É de se ponderar que, com uma proposta nova de intervenção pedagógica e formação para o ensino da álgebra, o uso de softwares que utilizam as representações gráficas, por exemplo, como o GeoGebra, o uso de dispositivos móveis como alguns utilizados no dia a dia dos estudantes, pode ser importante, contribuindo, desse modo, com os processos de ensino e de aprendizagem desse objeto matemático e, por fim, ter um melhor desempenho nos itens referentes.

\section{REFERÊNCIAS}

BREUNING, R. T.; NEHRING, C. M. Análise de questões do SAERS e o ensino da álgebra na perspectiva dos registros de representação. 2012 - Revemat: R. Eletr. de Edu. Matem. eISSN 1981-1322. Florianópolis, v. 07, n.1, p. 48-61, 2012.

CARVALHO, L. P. Um estudo das concepções de estudantes de ensino médio sobre o conceito de função com base na teoria dos registros de representações semióticas. / Lidiane Pereira de Carvalho. - 2017. Dissertação (Mestrado) - Universidade Federal de Pernambuco, Programa de Pós-Graduação em Educação em Ciências e Matemática, 2017.

DAMM, R. F. Registros de Representação. In: MACHADO, S. D. A. (et al.). Educação Matemática: uma introdução. - São Paulo: EDUC, 1999.

DUVAL, R. Registros de representação semiótica e funcionamento cognitivo do pensamento. Trad. MORETTI, M. T. Revemat, v.7, n. 2, Florianópolis: UFSC/MTM/PPGECT, p. 266297, 2012c.

\section{DUVAL, R. Registros de Representação Semiótica e Funcionamento Cognitivo da} Compreensão em Matemática. In: MACHADO, S. D. A. (org.) Aprendizagem em Matemática, Registros de Representação Semiótica. Campinas: Papirus, p. 11-33, 2010. (Coleção Papirus Educação).

KARRER, M. Articulação entre álgebra linear e geometria: um estudo sobre as transformações lineares na perspectiva dos registros de representação semiótica. São Paulo, 2006. 435 f. Tese (Doutorado em Educação Matemática) — Programa de Pósgraduados em Educação Matemática, Pontifícia Universidade Católica - PUC/SP, São Paulo, 
2006. Disponível em: < https://tede2.pucsp.br/handle/handle/11068 >. Acesso em: 23 setembro 2020.

LUCKESI, C. C. Capítulo II: Avaliação Educacional Escolar: para além do autoritarismo. In:__. Avaliação da aprendizagem escolar. 7ed. São Paulo: Cortez, 1998 [1994]. P. 2747.

MAGGIO, D. P.; SOARES, M. A. S.; NEHRING, C. M. Registros de representação semiótica da função afim: análise de livros didáticos de matemática no ensino médio. 2010 - Revemat: R. Eletr. de Edu. Matem. Eissn 1981-1322. Florianópolis, v. 5, n 1, p. 38-47, 2010.

PERNAMBUCO. Secretaria de Educação de Pernambuco. SAEPE-2017/Universidade Federal de Juiz de Fira, Faculdade de Educação, CaEd. V.1 (jan./dez.2017), Juiz de Fora, 2017 - Anual. Conteúdo: Revista do Professor - Matemática. ISSN 1048-560X.

PERNAMBUCO. SAEPE - 2019/ Universidade de Juiz de Fora, Faculdade de Educação, CAEd. V.1 (2019), Juiz de Fora - Anual. Conteúdo: Revista do Professor - Matemática. ISSN $1948-560 X$.

SALGUEIRO, N. C. G. Como estudantes do ensino médio lidam com registros de representação semiótica de funções. 2010. 132f. Dissertação (Mestrado em Ensino de Ciências e Educação Matemática) - UEL/PR, Londrina.

RICHARDSON, R.J. Pesquisa social: métodos e técnicas. São Paulo: Editora Atlas, 1999.

ZUCCO, J. Funções Monotônicas: Alunos da $3^{\text {a }}$ série do ensino médio frente as olímpiadas de matemática das escolas públicas. 2010. Dissertação (Mestrado) - Pontífica Universidade Católica de São Paulo, São Paulo. 